\section{National Latinx AIDS Awareness Day - October 15, 2018}

National Latinx AIDS Awareness Day (https://www. cdc.gov/Features/LatinoAIDSAwareness), October 15, is observed each year to focus on the continuing and disproportionate impact of human immunodeficiency virus (HIV) infection and acquired immunodeficiency syndrome (AIDS) on Hispanics/Latinos in the United States. The prevalence of diagnosed HIV infection among Hispanics/Latinos is approximately twice that among non-Hispanic whites $(1)$. The percentage of persons with diagnosed infection who are virally suppressed $(<200$ copies of HIV RNA per $\mathrm{mL}$ of blood) is lower among Hispanics/Latinos than among non-Hispanic whites (2).

An analysis of clinical outcomes among Hispanic/Latino participants in CDC's Medical Monitoring Project (2013 and 2014 cycles) found that a significantly higher percentage of women (78\%), compared with men (54\%), were living in poverty (3). However, women and men were equally likely to have received prescriptions for antiretroviral therapy (95\% versus $96 \%)$ and to have durable viral suppression (68\% versus $73 \%)$ (3).

National Latinx AIDS Awareness Day is an opportunity to encourage increased HIV prevention activities among Hispanics/ Latinos. CDC supports testing; linkage to, and engagement in, care and treatment; and other efforts to reduce the risk for acquiring or transmitting HIV infection among Hispanics/Latinos. Additional information is available at https://www.cdc.gov/hiv/ group/racialethnic/hispaniclatinos/index.html.

\section{References}

1. CDC. HIV surveillance report, 2016; vol. 28. Atlanta, GA: US Department of Health and Human Services, CDC; 2017. https:// www.cdc.gov/hiv/library/reports/hiv-surveillance.html

2. CDC. HIV surveillance supplemental report, 2018; vol. 23, no. 4. Atlanta, GA: US Department of Health and Human Services, CDC; 2018. https://www.cdc.gov/hiv/library/reports/hiv-surveillance.html

3. Luna-Gierke R, Shouse R, Luo Q, Frazier E, Chen G, Beer G. Differences in characteristics and clinical outcomes among Hispanicl Latino men and women receiving HIV medical care-United States, 2013-2014. MMWR Morb Mortal Wkly Rep 2018;67:1109-14.

\section{Differences in Characteristics and Clinical Outcomes Among Hispanic/ Latino Men and Women Receiving HIV Medical Care - United States, 2013-2014}

Ruth E. Luna-Gierke, $\mathrm{MPH}^{1}$; R. Luke Shouse, $\mathrm{MD}^{1}$; Qingwei Luo, $\mathrm{MS}^{1,2}$; Emma Frazier, $\mathrm{PhD}^{1}$; Guangnan Chen, $\mathrm{MD}^{1,2}$; Linda Beer, $\mathrm{PhD}^{1}$

The prevalence of diagnosed human immunodeficiency virus (HIV) infection among Hispanics/Latinos in the United States is approximately twice that of non-Hispanic whites (1). Barriers to, and experiences with, medical care have been found to vary by sex (2). Describing characteristics of Hispanics/Latinos in care by sex can help identify disparities and inform delivery of tailored services to this underserved population. Data from

\section{INSIDE}

1115 Vaccination Coverage for Selected Vaccines and Exemption Rates Among Children in Kindergarten United States, 2017-18 School Year

1123 Vaccination Coverage Among Children Aged 19-35 Months - United States, 2017

1129 Notes from the Field: Exported Case of Sin Nombre Hantavirus Pulmonary Syndrome — Israel, 2017

1130 Notes from the Field: Large Cluster of Verona Integron-Encoded Metallo-Beta-LactamaseProducing Carbapenem-Resistant Pseudomonas aeruginosa Isolates Colonizing Residents at a Skilled Nursing Facility - Chicago, Illinois, November 2016-March 2018

1132 Notes from the Field: Rubella Infection in an Unvaccinated Pregnant Woman — Johnson County, Kansas, December 2017

1134 QuickStats

Continuing Education examination available at https://www.cdc.gov/mmwr/cme/conted_info.html\#weekly.

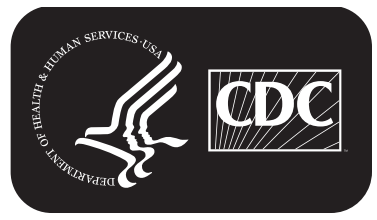

U.S. Department of Health and Human Services Centers for Disease Control and Prevention 